\title{
When welfare professionals encounter restructuring and privatization: The inside story of the probation service of England and Wales
}

\begin{abstract}
This article utilizes a multi-method case study of the probation service of England and Wales to explore the perspectives of practitioners and their union on how restructuring/privatization affected the probation profession. Professionals perceived restructuring/privatization as ideologically and politically motivated, rather than evidence-based in relation to service goals. Against this context, the article outlines the probation union's organized resistance, but ultimately its inability to halt the reform. The findings highlight practitioners' concept of 'the death of probation' created by philosophical opposition to privatization, but also by the splitting of their profession and the resultant assault on professionalism. The study underlines the unique aspects of restructuring/privatization in the specific service domain in particular those linked to working with a socially stigmatised client group, but it also has resonance for other public service professions facing the actuality or prospect of restructuring/privatization.
\end{abstract}

\section{Key words}

Professionals, professionalism, restructuring, outsourcing, probation, public services, privatization

\section{Introduction}

In 2015, the then Justice Secretary Chris Grayling, restructured and partly privatized the probation service of England and Wales against massive opposition from criminal justice experts, senior probation leaders, the unions representing probation workers, and the workers themselves. The exercise - Transforming Rehabilitation (TR) - went ahead without piloting 
and no meaningful consultation. The unions, among other stakeholders, predicted that a wellfunctioning public service would descend into chaos. The recent report of the Chief Inspector of Probation (England and Wales) provides damning evidence of multiple service failings post-TR attributed unequivocally to the splitting of the service and the outsourcing of the bulk of its work to private providers (HMIP 2019), some of whom have since closed down. On the one hand, probation stands as another example among many of the negative consequences for the workforce, as well as for the service, of a restructuring/privatization trend that has spanned more than three decades in and beyond the UK creating new organizational forms and introducing the 'logic of the market' to public services. On the other hand, in the main, core professional services have continued to be delivered by public sector employees, hence previous studies of outsourcing typically focus on peripheral activities (e.g. cleaning, catering, security, etc.) or on non-professional workforces in areas such as social care (Cunningham and James 2009). Thus, the probation case is rather unique in that it proffers a cautionary tale of the multiple dangers of splitting and partially privatizing a core service delivered by professional workers.

Along with structural changes, New Public Management has been another pillar of public service reform that has had particular consequences for professional workers in probation as elsewhere. Across public services, increased managerialism has gradually eroded professional control over service delivery and creeping de-professionalization processes have diminished the quality of work (Evetts, 2009; Exworthy and Halford, 1999; Hermann and Flecker 2012). Despite a large literature providing overviews of the transformation of public services and looking at both privatization and NPM theoretically, there are few studies offering in-depth analysis of professionals' lived experiences in specific organizational/occupational settings subject to these reforms (Thomas and Davies, 2005), especially in ones as radically and controversially restructured as that of probation (Walkers 
et al., 2019).

Utilizing findings from a multi-method case study of probation, this article provides an ‘inside story' of actors' responses to neo-liberal reforms told by union officers and practitioner-union members. This story contributes to analysis of the changing nature of professionalism and professional work within public services situated within the parallel trend of restructuring and privatization (Evetts, 2013). We discuss union efforts to contest and resist restructuring/privatization, how it violated practitioners' occupational values and assaulted their sense of professionalism to the point of regarding their profession as all but 'dead'. Specifically, we consider the capacity that the probation union and professionals themselves had to mediate, resist or adapt to changes in their work in the newly restructured environment (Ackroyd et al., 2007; Jonnergård and Erlingsdottir, 2012; Thomas and Davies, 2005). The article presents the 'voices' of union member-practitioners themselves within a moral economy lens (Bolton and Laaser, 2013) holding the moral purpose of probation central to the analysis. The research questions the article addresses are: (i) How did the union/professional association contest and resist TR in order to defend the profession's identity? (ii) How did union member-practitioners experience TR and how did it affect their sense of professionalism as well as practices of professionalism?

Next, based on existing literature the article discusses changing notions of professionalism in context of restructuring/outsourcing of public services, thus providing a broad conceptual and empirical canvas on which to locate the specificities of our research. We then outline the case of probation and describe our study. The findings are organised around three themes: (i) the union/professional association's defence of the probation profession; (ii) the metaphorical death of the probation profession; (iii) the assault on probation professionalism.

\section{Public service professionals in context of restructuring, privatization and outsourcing}


To assist our analysis of the empirical case study, we explored a number of debates around privatization and management of public services and their interconnected effects on professionals and professionalism. First, it is important to locate this discussion within a broader global political economy of reform of public services of which the UK among OECD countries was at the forefront (Pollitt, 2013). Indeed, Pollitt (2013: 475) describes the UK as "one of the club of Anglophone countries in which an ideology of 'management' has taken deepest root”. Many authors regard public service reform, as pursued via restructuring, privatization and New Public Management (NPM), as a neoliberal ideological project. That project began in the 1980s under the Thatcher-led Conservative government, and has since been pursued by Labour (1997-2010), Coalition (2010-2015) and Conservative (2010present) governments alike, if less dogmatically and more pragmatically under Labour (Ackroyd et al., 2007; Burke and Collett, 2016; Grimshaw et al., 2002; Smith, 2012). While successive British governments' stated aims were cost restraint and improved efficiency, effectiveness and utilization of public resources, there is little reliable evidence about any positive outcomes for citizens/society (Pollitt, 2013) as the case of probation only serves to highlight (HMIP, 2019).

Further, from a workforce perspective, many studies argue that outsourcing of public services has a strong tendency to lead to work intensification and diminished terms and conditions (Cunningham and James 2009; Grimshaw et al., 2015; TUC, 2015), as well as lower job quality including performance pressure, loss of autonomy and lower job satisfaction (Authors, XXXX; Cooke et al., 2004). Moreover, the TUC claims that there remains a risk of emergence of two-tier workforces where workers transferred to the private sector are protected by legal provisions covering transfers of undertakings, while newly hired workers get worse terms and conditions or workers are hired via agencies on a casualized basis (TUC, 2015). However, there are counterpoints to the generally bleak outlook. For instance, in a 
comparison of three service domains, Bach and Givan (2010) argue that outsourcing support services does not necessarily lead to the degradation of jobs and working conditions. In health and local authority sectors, co-existing with worker perceptions of the unsuitability of the profit motive in guiding their work, Hebson et al. (2003) also find some evidence of positive adaptation to the private sector associated with perceived opportunities for training and advancement. Such studies contend that it is the way that outsourcing is implemented, the way employees are treated, and what is on offer for them that matter.

In addition, NPM - another major component of public service reform - has been the focus of detailed attention in terms of its effects on professional workers. NPM replaces the traditional approach of groups of professional workers themselves regulating their collective knowledge, skills and expertise. Characterized by managerial practices commensurate with the core policies of disaggregation of public sector bureaucracies, introduction of competition and incentivization, NPM spread through public services in the 1990s (Leicht et al., 2007). The consensus shifted from desirability of professional self-regulation towards that of regulation from above or 'managed' services (Evetts, 2013). Scholars argue that a key common aim of reform, NPM in particular, has been to reduce the traditional autonomy and independence that public service professionals enjoyed (Kirkpatrick and Ackroyd 2003), and replace it with a more active managerial function especially in welfare state institutions where neo-liberals considered that professionals had too much power and self-interest (Ackroyd et al., 2007). Thus, the promotion of new attitudes and values as well as new professional and managerial subjectivities for public service professionals also featured in NPM discourse (du Gay, 1996; Exworthy and Halford, 1999). This shift is manifest in the way that many public service professionals are now forced to work in more accountable, evidence based and standardized ways under enhanced managerial control and supervision (e.g. Ackroyd et al., 2007; Bolton, 2004; Kirkpatrick and Ackroyd, 2003; Noordegraaf, 
2016). These changes have undermined the traditional autonomy, discretion, collegiality, legitimacy, expertise, authority, seen as integral to professional work and valued by professionals (Evetts, 2013), including in our research site of probation (Eadie, 2000; Fitzgibbon and Lea, 2014; Gale, 2012).

However, there are outliers to this general shift towards managerial as opposed to professional control. It is argued, for example, that hospital doctors are the owners of irreplaceable expertise and hence they are able to 'bend the organizational rules' imposed by managers (Correia, 2016). Similarly, in the case of social workers, Lavalette (2007) argues that despite the increasing domination of managerial practices, there remains space for frontline professionals to use their expertise to act in ways that they deem beneficial to service users. In addition, social services departments have used the existing professional hierarchy to implement managerialism rather than establishing a new management cadre (Ackroyd et al., 2007). This is similar to the case of probation (Mawby and Worrall, 2013) prior to the restructuring/outsourcing discussed here.

Consideration of professionals' subjective values requires an alternative lens to political economy, which cannot fully illuminate lived experiences in different domains. For Bolton and Laaser (2013), moral economy connects analysis of political economy - as per the broader context of public services reform described above - and the lived reality of people's everyday work situations and is therefore able to reveal the way political, economic and social regimes play out in different sites. It enables exploration of 'reflective actors who care ... about each other, about the work they do, the recognition they receive for it and the communities they create' (Bolton and Laaser, 2013: 511). Thus, the analytical emphasis shifts to the actors operating in their specific context as our emphasis does in this article. Such a perspective has the capacity to 'breathe life' into the political economy framework 
(Bolton and Laaser (2113: 511) that dominates literature on public services reform.

Highlighting actors is especially important for contexts such as social work and probation where professionals' moral values and subjectivities influence specific responses, including collective contestation and resistance, to attempts to shift to a 'managed service' model. In the probation case, prior to restructuring and outsourcing, influenced by their moral ethos, practitioners and their union seemed to have managed to act to moderate the managerialism associated with earlier reforms (McKnight, 2009; Mawby and Worrall, 2013). They had also succeeded in maintaining the traditional approach of deep engagement with individual clients that their professional values demand (Gregory, 2010).

When it comes to professionals' capacity to resist or contest reform and resulting threats to professionalism, few studies explore the role/action of unions/professional associations in any depth. Anon and Author A (XXXX) write that the 'crucial relationship' between professional commitment and unionism as well as unions' role in upholding professional standards are under-explored in the literature on professions and change. Yet, they argue, as the state attempts to wrestle control from professionals, they may turn to their union as a vehicle for collective resistance (ibid: 190). As Lavalette (2007: 201) contends, professional values do not necessarily clash with collective organization, and professionalism can be a mobilizer of protest and discontent. Further, in the healthcare context, Hendrikx and Gestel, (2017) find that having a proactive professional association contributed towards GPs being relatively successful in safeguarding their autonomy against external interference. Thus, in some cases unions/professional associations remain important actors contesting the neoliberal reform project and its effects on professional workers. At a broader level, unions have played with some success a crucial role in recent campaigns to protect public services from privatization, especially the NHS. Unions have also managed, at a time of diminished membership and weaker structural and institutional resources, to mobilize members to take strike action and 
participate in demonstrations in support of such campaigns (Coderre-LaPalme and Greer 2018).

\section{Restructuring and outsourcing probation: Transforming Rehabilitation}

With stated aims of overhauling the system in order to reduce reoffending and protect the public, in June 2014, Transforming Rehabilitation (TR) split probation, previously delivered by 35 semi-autonomous Probation Trusts operating under the National Offender Management System (NOMS), into two parts. One part remained in the public sector in a newly centralised National Probation Service (NPS) within the civil service; the other part was later outsourced (February 2015) to the private sector via 21 regionally based Community Rehabilitation Companies (CRCs). The service split was according to offender profiles: work with low to medium risk offenders outsourced via CRCs, while the NPS deals with high-risk offenders.

About 54 per cent of probation staff transferred to CRCs and 46 per cent to NPS (MoJ, 2015). The vast majority of those transferred to NPS were the fully qualified practitioners (dealing with high-risk offenders) - Probation Officers (POs) and Senior Probation Officers (SPOs) while the lower grade and less qualified Probation Service Officers (PSOs) mostly transferred to CRCs. Those transferred to CRCs work under highly detailed performance contracts as seen in the outsourcing of other public services including a payment-by-results component (Hebson et al., 2003). Those transferred to NPS are now subject to civil service policies including the 'E3 programme' (Effective, Efficient, Excellent) used to define and implement the changes deemed necessary to achieve a consistent way of working across NPS after several years of devolvement to Probation Trusts. Thus, the new structural arrangements have brought about significant changes in working practices for both parts of probation. 
Indeed, TR is widely recognized in the criminal justice community as the most trenchant and challenging reform ever seen in probation with myriad implications for frontline professionals (see Deering and Feilzer, 2015; Annison et al., 2014; Robinson et al., 2015). However, it is important to acknowledge that NPM and the general drift towards managed services had encroached on probation practice beforehand. In addition, other major probation reforms had also significantly affected the work and identity of the probation profession. Of particular note, in moves that signalled an official shift in purpose from individual rehabilitation towards risk management and public protection (Deering and Feilzer, 2015), in 1995, the Conservative government withdrew probation training from social work and in 1997 moved probation from the social work apparatus altogether to criminal justice. Labour subsequently (2004) brought together prison and probation services under the unified correctional umbrella of NOMS. However, against these previous reforms, the resilience of the probation profession ensured that practitioner values continued to guide frontline practice (McKnight 2009).

\section{Methods}

The access route to the profession was via the main probation union, Napo, which represented about 60 per cent of main grade probation practitioners. The study involved multiple methods, qualitative and quantitative. Qualitative fieldwork occurred mainly from February to July 2015 after the implementation of Transforming Rehabilitation (TR). The timing meant that we were observing real-time change and participants were able to give testimonials about the unfolding impact of TR on their professional lives. Individual semistructured interviews lasting between 1-1.5 hours took place with nine national Napo officers and 29 lay branch officers (serving probation professionals) from 17 of 21 Napo branches. Visiting many probation workplaces around the country allowed us to witness practitioner- 
client interactions, workplace conditions, as well as to interact informally with clients/practitioners. In order to mitigate the risks of developing a skewed picture by virtue of gathering only the views of the most highly union active practitioners, we also held small focus group discussions with around 60 non-office holding Napo members. In addition, we observed and participated in several union events, including national conferences and branch meetings over an 18-month period that were attended by office-holding and non-officeholding Napo members alike. Interviews and focus group discussions were transcribed verbatim, and the qualitative research software package NVivo was used to store, thematically code and manage the data.

A Napo membership survey conducted in summer 2015 gave us the experiences and views of a larger population of unionised probation practitioners, but beyond those most active in the union. This enabled us to evaluate the magnitude of particular problems and challenges facing probation professionals. The survey questions focused on the post-TR environment covering issues related to working conditions, workplace culture, probation careers, and the role of the union. The survey attracted 992 responses, representing a 17.5 per cent response rate. Using the statistical software programme Qualtrics, findings were analysed with frequencies and cross-tabulations to enable us to see differences of opinion/experience among groups of practitioners.

\section{Research findings: the inside story of probation restructuring/privatization}

From the study, three core themes were identified that interconnect to reveal the profound effects of TR on the probation profession's work and identity.

\section{The union/professional association mobilises against TR}


Jonnergård and Erlingsdottir (2012) argue that a profession's identity is often constructed and maintained by professional associations, while Hendrikx and Gestel (2017) find that professional associations may offer some safeguarding against external interference. In the case of the probation profession, Napo doubles as probation union and professional association; therefore, it is important to consider its attempts to defend the profession's work and identity. As the 'voice' of probation for many years (McKnight, 2009), Napo had helped to engender a deeply collectivist culture within the probation profession. For many, if not most probation practitioners, their union affiliation is reflected in their professional identity and vice versa in a mutually reinforcing relationship (Author A, XXXX; Anon and Author A, XXXX). Support for Napo was strong as exemplified by the following quotation:

'I am a believer in the union movement and particularly in Napo because it's specialist to what I do. The fact that we're running an AGM every year and we're passing motions about practice, about how we do the face-to-face work with the offenders, about how we keep our moral standards, how we keep our rapport with the offenders professional.' (PSO, CRC, female)

Strong membership support had been the bulwark behind Napo's longstanding efforts to defend the probation profession that had entailed condemning and lobbying against several previous reforms constructed as politicised 'attacks' detrimental to the profession and its clients, and introduced without consultation with professionals and their representatives (Gale, 2012; McKnight, 2009). Similarly, in the pre-implementation phase of TR, the Government approach was to ignore the concerns expressed by the profession and was therefore guaranteed to attract union opposition. The union's opposition campaign comprised three strategies that aimed to compel the government to pull back from TR. 
The first strategy was to mount a communications offensive contesting the notion that TR was either necessary or desirable (General Secretary's blog, newsletters, press releases). The union invoked the fact that successive National Audit Office reports had praised the work of probation as evidence of the ideological nature of the restructuring/outsourcing (see also Burke and Collett, 2016). Napo's leadership was acutely aware that with a Conservative-led coalition government and a controversial justice secretary, it was operating within a hostile political context driven by neo-liberal ideology. An extract from the Napo General Secretary's online blog exemplifies in principle opposition to TR and the union's preparedness to vocalise such to the extent of vilifying the government minister responsible:

'Chris Grayling took over the post of Justice Secretary in 2012. In two years, he has wreaked havoc on the justice system imposing his ideology against rational argument from a broad range of professionals and stakeholders.' (May 2015)

Branch officers' views aligned with those of the national leaders' that TR constituted an ideological assault against a highly unionised profession:

'... the damage to Napo has been significant and I don't know if that was an intent or not, but whether it was or it wasn't I don't think this government is sorry that that's been an outcome.' (SPO, CRC, female)

It was clear that the overwhelming view among national and branch officers alike was that TR would destroy the profession. However, the union needed to navigate carefully in order to keep 'ordinary' members on side with any action it took and to garner wider support at a time when public opinion was unfavourable towards the use of strike action (Coderre-LaPalme and Greer 2018). The perceived need to woo the media in order to get the story into the public domain influenced the union's emphasis on public risk as its main narrative of 
contestation, which senior leaders felt would attract more public outcry than workers' plight or even the effects on offenders. At the risk of losing their jobs after a ban on them speaking to the media, some probation union member-practitioners stepped forward to speak out against TR feeling that it was their moral duty as part of their professionalism. The union was relatively successful at gaining sympathetic media attention considering that most people have no contact with probation and therefore, potentially little interest in it.

The second strategy - initiating a Judicial Review of TR - also foregrounded public safety together with professionals' health and safety issues, but was ultimately reluctantly withdrawn based on legal advice to the union about the huge costs of the action versus the very low likelihood of success. The third strategy - strike action, traditionally considered a key weapon in unions' armoury - proved somewhat problematic partly because probation practitioners do not have a history of militancy. The first of two strikes against privatization was only the fourth strike in Napo's approximately 100-year history. Officers and ordinary members alike expressed that probation staff did not and would not take strike action lightly because of the negative impact on client services. This standpoint of moral dilemma highlights probation practitioners' concept of professionalism. Napo framed the strike action as largely about that same professional issue - the adverse impact TR would have on clients and rehabilitation efforts as well as public risk.

The first one-day strike in 2013 took place after an overwhelming majority (80\%) of members voted in favour on a 46 per cent turnout demonstrating the strength of opposition to TR. Moreover, in some regions probation chief executives also supported the action, which gave extra impetus to members to participate as well as highlighting the shared professional values within the probation hierarchy. In interviews and other fora, Napo officers described an 'incredible', 'amazing' and 'unprecedented' amount of member support for the strike, 
which involved large demonstrations in towns and cities around England and Wales. The second strike took place some six months later early in 2014 over 1.5 days and officers described it as 'more contentious', 'deeply unpopular' and less well supported. Branch officers felt that the optimistic mood of the first strike had waned because members' hopes of the action stopping TR were dashed as the government ploughed on with the plans. Thus, it appeared that for this less powerful professional group the proactive professional association did not provide the safeguarding experienced by others (Hendrikx and Gestel, 2017). Nevertheless, those who participated in the second strike reported finding it empowering to 'down tools' and walk out half way through a working day. Many saw it as an important form of protest and expression of symbolic opposition to TR even while recognising that the justice secretary and the government were riding roughshod over the profession's concerns. Ultimately, the union's historic attempts at organized resistance did not achieve the desired outcome and the identity of the probation profession was threatened. However, participating in strategies of resistance/opposition did not transgress professionalism rather it was a necessary component of professionalism in order to defend the profession's identity.

\section{Restructuring and privatization cause the metaphorical 'death of probation'}

There was an intense debate among practitioners in online forums as well as at Napo events about 'the death of probation', a metaphor that represented the widespread feeling that practitioners no longer recognised or identified with the purpose of their profession. "This isn't the job I trained to do" became a familiar refrain as we carried out our fieldwork that highlighted how the identity of the profession had been 'killed'. While researchers have argued that direct attack on probation has been relentlessly pursued since the late $1980 \mathrm{~s}$ (Aldridge, 1999; Gale, 2012; Mawby and Worrall, 2013), probation practitioners in our study 
saw this latest reform as the deepest yet and what is more, entirely antithetical to their values as expressed below:

'The whole idea of making money out of people's acts of crime and the fall-out from it is I think for many people quite disturbing ... it shouldn't be a money making operation. I have colleagues who were morally upset at the idea because some of the companies that were bidding were involved in arms and all sorts of different businesses.' (PSO, CRC, male)

The deeply held moral component of practitioners' professional identity is readily apparent in the above quotation. An overwhelming majority of practitioners involved in the study $(71 \%$ of survey respondents, in both services equally - Table 1) believed that the profit motive would inevitably corrupt client-oriented probation values. However, as the quotation above implies, more than this, it was the type of companies selected which included some involved in morally dubious activities as well as others with a perceived conflict of interest arising from holding a prison portfolio:

'I truly believe that offenders will receive a poorer service and staff will struggle to provide the high level of service they have always given. Consequently, the public will be at risk. I also believe companies should not be able to profit from illegal acts of others - they will have a vested interest in people committing crimes, especially when they also own prisons.' (SPO, CRC, female)

The other main factor causing the 'death' of probation for practitioners' was the way that TR split the previously integrated profession in two. Although other public services (e.g. the NHS) have fragmented thanks to restructuring and outsourcing (Leicht et al., 2009), there is no precedent for the splitting in two of a necessarily integrated public service requiring close 
co-ordination in order to fulfil its main purposes (HMIP, 2019). For example, poor communication across the service (see Table 1) produced by the split posed serious public safety risks:

'[TR] has caused a rift between CRC and NPS that will in the long-term prove to be more costly with greater opportunity for malpractice and a lack of accountability. I do not consider that we are in a position to protect the public, but we will be the scapegoats when tragedies happen.' (SPO, CRC, female)

In addition, the case related by a Napo officer of a female CRC PSO attacked during a supervision session by a supposedly low risk sex offender, illustrated the potential risks for staff. The PSO in question had not seen the offender's previous supervision record since it was incorrectly on the NPS database that she could not access. In addition, she was also unable to communicate with NPS staff about the case. Although the CRC attributed this episode to operational 'teething' problems, the point that union officers made is that it is far from uncommon for risk profiles to be ambiguous or for risk to escalate. Practitioners experienced in both low-risk and high-risk cases frequently need the opportunity to work together, as under the former Trust arrangements, to resolve these kinds of professional challenges:

'You would never feel great about it, you would always feel that was a failure for you as a professional, but you could in some way start to remedy it ... people can't do that anymore. It feels like on top of that failure you can't try and resolve it and it's horrible to see how undermining that is for experienced practitioners ... it is their professional identity that feels like it's being demolished basically.' 
Thus, many practitioners perceived the split of risk categories as dangerous but also as 'deprofessionalizing' CRC staff, which in itself many experienced as not merely stressful, but also as an attack on the learning and socialization processes specific to the professional group. In a context where formal probation officer training has been eroded incrementally, the impoverishment of informal training opportunities might reinforce the idea that rehabilitation is a technical activity that can be delivered by anyone (Tangen and Briah, 2018). Napo was a fierce critic of the TR proposals that had stated that while NPS would be expected to employ professionally trained probation staff, CRCs would only be expected to provide a workforce with unspecified 'appropriate levels of training and competence' (Deering and Feilzer, 2015: 10). Some practitioners felt that the pool of collective professional knowledge had already reduced in many CRC workplaces, partly caused by spikes in leaver rates and new unqualified staff entering.

Another dimension of the 'death' of probation identity was the threats posed by new arrangements for the management of the service. Practitioners valued that historically probation was self-managed by their professional community; the support of some chief executives for the strike action was also reflective of how the concept of self-management pervaded the culture of probation. Self-management meant that middle and senior managers generally worked as, with and among practitioners to preserve, rather than undermine professional control, norms and values, in particular the moral purpose of probation (also see: Ackroyd et al., 2007; Fitzgerald and Ferlie, 2000). Self-management also meant that SPOs who were (and are) practitioners on the first rung of the managerial ladder, sought to disassociate themselves from a manager identity, preferring to see themselves as senior practitioners who co-ordinated work, supported other practitioners, rather than managed people per se (similar to nurse-manager identities, Bolton, 2005). Post-TR, the concern expressed was that the SPO role was now co-opted into managerial work and had become 
more about implementation of managerial protocols and targets than oversight of professional practice. Besides, practitioners in both parts of the service complained that they were under newly recruited managers whom they regarded as unqualified to manage probation (see also Smith, 2012). NPS practitioners were managed by senior officers mostly from the Prison Service, while their CRC 'colleagues' were under direction of people with little or no organizational/professional/managerial experience of criminal justice/welfare activities let alone probation.

\section{TR assaults professionalism}

The relationship with clients is central to probation professionalism, therefore how TR altered that relationship merits detailed attention. To begin with, the widespread preference for use of 'client' over the official term 'offender' reveals much about practitioners' concept of that relationship. Most practitioners sought to humanise their clients, positioning them as people who had made mistakes, rather than as fundamentally 'bad'. This was a way of discursively de-stigmatising their clients and hence their work, thus seeking to avoid the taint associated with this type of 'dirty work' (Ashforth and Kreiner, 2014). Practitioners spoke passionately about how collaborative, meaningful relationships between professional and client could change offending trajectories leading to desistance and rehabilitation:

\footnotetext{
'A lot of us still passionately believe in the work that we do. We still feel that we make a difference ... in fact we know we make a difference because we see it, we live this stuff ... governments come, governments go, things change...' (SPO, NPS, male)
}

Practitioners were also highly cognisant of the fact that the customer service ethos that we witness in other public services such as healthcare (Bolton, 2004) which some of the private 
providers were emulating, is not possible in probation where 'clients' do not have any choices about when, where and how to engage with the service:

'They [CRC owners] demonstrate little understanding of client need and believe they can run the service as a customer focussed company, but clients do not choose to come to us.'

Apart from damaging practitioners' self-concept of professionalism rooted in the capacity to make a difference to socially stigmatised individuals, the shift in purpose also pervaded their everyday work. For example, there was an imposed reduction in both parts of probation in time allocated to offender supervision, which a substantial minority $(36 \%)$ of survey respondents, especially POs mostly dealing with high-risk offenders, described as too little (Table 1). The 'conveyor belt' conditions described as especially intense in the CRCs stood in contrast to the previous latitude practitioners had about how to allocate work time to different tasks. Instead of prioritising the needs of individual clients, they were now required to work in the name of 'organizational excellence', which could mean having to compromise what they regarded as professional standards (36\% of survey respondents - Table 1$)$ in order to meet unrealistic targets (54\% of survey respondents - Table 1$)$.

Practitioners remained resolute that professional knowledge and judgement would always be necessary to deliver an effective probation service (Ackroyd et al., 2007; Flynn, 1999) not least because of the inherently unpredictable nature of the client group similar to others such as hospital patients (Bolton, 2004). However, having less time for professional reflection (59\% of survey respondents, $67 \%$ of POs - Table 1) and less time to discuss cases with colleagues (33\% of survey respondents - Table 1) inevitably diminished practitioners' capacity to engage deeply with clients and their needs. 


\section{TABLE 1}

Questions were raised repeatedly around whether the deep engagement with clients that probation professionals valued so much could survive TR either in the CRCs (with the profit motive) and in the highly pressurised and centralised NPS:

'I'm now at the end of my tether ... and the only thing that keeps me in the job is the work that I do with my offenders ... a lot of my caseload is people that I've been working with for a long period of time ... mainly lifers.' (PO, NPS, male)

The pessimism expressed by the overwhelming majority about impact on work with clients was countered by a tiny number of probation professionals particularly younger, newer ones, trained under the risk management approach rather than the social work framework (Mawby and Worrall, 2013). Some of these expressed that they had thought TR might proffer some benefits for clients so they felt prepared to make some trade-offs (e.g. morally accepting private sector involvement). TR's claim to allow greater scope for innovation was attractive for them, particularly for work with low risk offenders such as drug users and other prolific offenders whose recidivism rates are high and therefore work with them frustrating. A tiny number stood by this viewpoint post-TR:

'There will be more opportunities because the CRCs will be doing different things like resettlement work, resettlement teams, which will involve more education, employment, housing issues, for example, so there will be more of an interface with those bits of the work.' (SPO, CRC, male)

In the NPS, TR offered fewer opportunities for sustaining let alone developing innovation because of the centralised, top-down nature of the civil service. The following NPS 
interviewee highlighted the lack of 'localism' as a major brake on innovative practices that individuals could introduce before TR:

\footnotetext{
'We've been used to being in quite small probation trusts, very enmeshed with other local agencies and services, lots of partnership working. When I was a women's specialist, I was located at the women's centre and we worked in partnership with them. That has all gone.'
}

In summary, TR assaulted probation professionalism in many ways that were capable cumulatively of eroding the profession and in the process diminishing a previously wellfunctioning core public service activity.

\section{Discussion and conclusions}

This article joins a longstanding debate about changes in professions and professionalism within an altering public service context profoundly affected by the neoliberal reform project begun by the Conservative government in the 1980s. A political economy lens draws attention to the broader forces influencing structural reform of public services. It tells us that the privatization project was and remains an ideological one not least because of the absence of evidence that it delivers the promised service improvements and reductions in costs, quite the contrary in the probation service and beyond (HMIP, 2019; Pollitt, 2013; Robinson et al., 2015; Walker et al., 2019). Our case study of probation contributes an empirically grounded analysis of a small niche profession that attracts little academic attention beyond the criminal justice literature. Probation extends the broader debate by identifying specificities and nuances that stem at least in part from the socially tainted nature of the work (Ashforth and Kreiner, 2014), but also from the radical restructuring exercise that split the profession in two and damaged its identity via partial privatization. 
Probation represents a case study of a profession with a profoundly moral purpose that works for the benefit of clients, but that also serves the public good insofar as improving rehabilitation and reducing recidivism are social benefits (Robinson et al., 2017).

Furthermore, probation provides a study of a less powerful professional group than those usually focused upon in the public services professionalism literature (medicine and law) (Evetts, 2013) whose 'clients' are themselves socially stigmatized and largely invisible to mainstream society (Fitzgibbon and Lea, 2014; Mawby and Worrall, 2013). The restructuring/privatization of probation is unprecedented in terms of its scale and scope and it has proven to be something of an unmitigated disaster for professionals as well as other stakeholders (see HMIP, 2019). Thus, we argue that it is important that the story appears in the work and employment literature as well as elsewhere.

The article makes three main contributions to research and theory on professional groups and reform of public services. Firstly, the study adds a novel dimension by foregrounding the interconnection between unionism and professionalism as well as the profession's organized contestation of and resistance to restructuring/privatization mounted in the manner of an ideological battle for the very purpose and identity of probation. Previous research rarely offers this union perspective even though the environments studied (e.g. healthcare) are often at once professional and highly unionised. Our research in probation shows that unions representing professional workers, especially those doubling as professional associations (such as Napo), play a crucial role in constructing and defending a profession's identity not merely workers' terms and conditions. Napo has always 'spoken up' publicly for probation throughout a series of reforms that practitioners perceived as detrimental (McKnight, 2009), relentlessly and assertively pursuing members', clients' and public interests in tandem, rather than merely defending workers' rights as one might assume of a union. We argue that this has created an occupational culture of solidarity such that union membership and activism are 
intricately entwined with probation practitioners' professional identity resulting in the assault on the profession being seen as an assault on the union and vice versa. Nevertheless, in the face of a union hostile government, Napo's campaign of opposition could not ultimately prevent the splitting and partial privatization of the probation service. This only serves to highlight the political economy within which TR occurred and specifically the greater power of the state in the contemporary era vis-à-vis unions/professional associations, particularly historically less militant ones.

Secondly, practitioners' voices lead us to be concerned that the state's Transforming Rehabilitation project constituted the metaphorical 'death' of the probation profession as practitioners self-defined it. Practitioners rejected the government promulgated benefits of TR and saw it as ideologically and politically motivated, rather than evidence-based (Burke and Collett, 2016; Robinson et al., 2017). This standpoint is now vindicated by the report of the Chief Inspector of Probation (HMIP, 2019). Moreover, contrasting with previous research that identifies professionals' mixed attitudes towards neo-liberal reforms including privatization (Fitzgerald and Ferlie, 2000), probation practitioners' displayed firmly united philosophical opposition. We argue that this widely shared opposition is attributable to the common values and moral purpose of this integrated professional, highly unionized group. It was quite clear that probation practitioners perceived the ethic of care and humanistic sensibility towards clients that are so central to the profession's identity (Mawby and Worrall, 2013) as existentially threatened by introduction of the profit motive (Walkers et al., 2019). In contrast to other settings (e.g. Bach and Givan, 2010; Hebson et al., 2003), no matter how TR had been implemented or what had been on offer to practitioners, this would have been the perception. In addition, practitioners in the privatized CRCs perceived that marketization removed the buffer that affirmed they were doing something socially worthwhile even if socially tainted or 'dirty' (Ashworth and Kreiner, 2014). Interestingly, it was the new 
structural environment, which threatened practitioners' psychological wellbeing and sense of professionalism rather than the socially tainted nature of the client group as sometimes suggested in the 'dirty work' literature (Ashforth and Kreiner, 2014). Thus, although the probation occupation will necessarily continue, as a profession practitioners considered it 'dead'.

Thirdly, we extend the explanatory lens beyond political economy in order to capture the lived experiences and subjectivities of professionals. The moral economy lens proposed by Bolton and Lasser (2013) with its emphasis on actors' subjectivities highlighted how the particular type of 'occupational professionalism' (Evetts, 2009) in probation was intricately connected to the fact that 'clients' are a stigmatized group at the margins of society. Offenders cannot be conceptualized as 'customers' in the way that the neoliberal version of public services calls for. Working with a stigmatized group has specific implications for professional behaviour (Ashworth and Kreiner, 2014). In this respect, and as found in previous research on probation (Annison et al., 2008; Eadie, 2000), we emphasise that our participants firmly believed that offenders benefited from long-lasting personal relationships with their probation officers, but restructuring and outsourcing impoverished ('destroyed') such deep client engagement that was so central to probation professionalism. Practitioners were passionate that any move to reduce interaction with individual clients was ill informed and had little to do with their self-defined core moral purpose of rehabilitating offenders. In this vein, we heard that TR fundamentally diminished the probation 'ideal' (Deering and Feilzer, 2015) with both parts of the service perceived as now framing probation work as about public risk management and punishment of offenders rather than rehabilitation.

However, amid the structural and working practice changes, we witnessed that practitioners were holding on to their own concept of professionalism, but it was getting increasingly 
difficult to enact this through everyday professionalism. Contrary to other more optimistic studies highlighting the potentiality of hybrid professionalism (Noordegraaf, 2007; Turner et al., 2016), our study of lived experiences reveals the difficulties facing less powerful professionals, less able to assert their autonomy even when a strong union/professional association is advocating for them (Anon and Author A XXXX). Maintaining their professional community at the micro-level of practices and identity building proves far more challenging than for more powerful professions (Jonnergård and Erlingsdottir, 2012), despite strong workplace unionism (Author A and B, XX).

To conclude, this article contributes to theoretical and empirical research that challenges the benefits of privatization and exposes the damaging effects on a profession's identity in ways that have far-reaching ramifications for professionalism and hence service delivery. Yet many of the practitioners we spoke to talked optimistically about the historic resilience of the probation profession in the face of regular 'assaults' (McKnight, 2009). Following the scathing report of the Chief Inspector of Probation, and amid plans for further reforms including ending CRC contracts early (HMIP, 2019), whether or not that resilience will prove sufficiently strong for the probation profession's identity to be revived will no doubt be a topic for future research.

\section{Acknowledgements}

We are grateful to Napo for facilitating access to probation practitioners and for providing a wealth of information. We also thank all the union member-practitioners who participated in our study.

\section{References}


Aldridge, M (1999). 'Probation Officer Training, Promotional Culture and the Public Sphere.' Public Administration 77(1): 73-90.

Annison, J., Eadie, T. and Knight, C. (2008). 'People First: Probation Officer Perspectives on Probation Work.' Probation Journal 55(3): 259-271.

Annison, J., Burke L. and Senior, P. (2014). 'Transforming Rehabilitation: Another example of English “exceptionalism” or a blueprint for the rest of Europe?' European Journal of Probation 6(1): 6-23.

Ashforth, B. and Kreiner, G. (2014). 'Dirty Work and Dirtier Work: Differences in Countering Physical, Social, and Moral Stigma.' Management and Organization Review 10(1): 81-108.

Bach, S. and Givan, R. (2010). "Regulating employment conditions in a hospital network: the case of the Private Finance Initiative." Human Resource Management Journal 20(4): 424439.

Bach, S. and Stroleny, A. (2017). 'A Tale of Two Cities: Employer and Trade Union Responses to Local Government Retrenchment in Britain.' Sociologie du Travail 59(1) doi.org/10.4000/sdt.544.

Bolton, S. (2004). 'A Simple Matter of Control? NHS Hospital Nurses and New Management.' Journal of Management Studies 41(12): 317-333.

Bolton, S. and Laaser, K. (2013). 'Work, employment and society through the lens of moral economy.' Work, Employment and Society 27(3): 508-525. 
Burke, L. and Collett, S. (2016). 'Transforming Rehabilitation: Organizational bifurcation and the end of probation as we knew it?' Probation Journal 63(2): 120-135

Cooke, F.L., Earnshaw, J., Marchington, M., Rubery, J. (2004). "For better and for worse: transfer of undertakings and the reshaping of employment relations." International Journal of Human Resource Management 15(2): 276-294.

Correia, T. (2016). 'Doctors' reflexivity in hospital organisations: the nexus between institutional and behavioural dynamics in the sociology of professions.' Current Sociology 65(7): 1050-1069.

Cunningham, I. and P. James (2009). "Strategies for union renewal in the context of public sector outsourcing." Economic and Industrial Democracy 31(1): 34-61.

Deering, J. and Feilzer, M. (2015). Privatising Probation. Is Transforming Rehabilitation the end of the probation ideal? Bristol, Policy Press.

Eadie, T. (2000). 'From befriending to punishing.' Professionalism, Boundaries and the Workplace. N. Malin. London and New York, Routledge: 158-177.

Evetts, J. (2009). 'New professionalism and new public management: changes, continuities and consequences.' Comparative Sociology 8: 247-266.

Evetts, J. (2011). 'Sociological analysis of professionalism: past, present and future.' Comparative Sociology 10(1): 1-37.

Evetts, J. (2013). 'Professionalism: Value and Ideology.' Current Sociology 61(5-6): 778796. 
Exworthy, M. and Halford, S. (1999). Professionals and the new managerialism in the public sector. Buckingham: Open University Press.

Fitzgerald, L. and Ferlie, E. (2000). 'Professionals: back to the future?' Human Relations 53(5): 713-739.

Fitzgibbon, W. and Lea, J. (2014). 'Defending probation: Beyond privatisation and security.' European Journal of Probation 6(1): 24-41.

Gale, J. (2012). 'Government reforms, performance management and the labour process: the case of officers in the UK probation service.' Work, Employment and Society 26(5): 822-838.

Gregory, M. (2010). 'Reflection and Resistance: Probation Practice and the Ethic of Care.' British Journal of Social Work 40: 2274-2290.

Grimshaw, D., Vincent, S. and Wilmott, H. (2002). 'Going privately: partnership and outsourcing in UK public services.' Public Administration 80(3): 475-502.

Hebson, G., Grimshaw, D. and Marchington, M. (2003). 'PPPs and the changing public sector ethos: case-study evidence from the health and local authority sectors.' Work, Employment and Society 17(3): 481-501.

Hendrikx, W. and van Gestel, N. (2017). 'The emergence of hybrid professional roles: GPs and secondary school teachers in a context of public sector reform.' Public Management Review 19(8): 1105-1123.

HMIP (2019). Report of the Chief Inspector of Probation. HM Inspectorate of Probation, London: March 2019. 
Jonnergård, K. and Erlingsdottir, G. (2012). 'Variations in professions' adaption of quality reforms: the cases of doctors and auditors in Sweden.' Current Sociology 60(5): 672-6

Kirkpatrick, I. and Ackroyd, S. (2003). 'Transforming the professional archetype? The new managerialism in UK social services.' Public Management Review 5(4): 511-531.

Lavalette, M. (2007). 'Social work today: a profession worth fighting for?' New Labour/Hard Labour? Restructuring and resistance inside the welfare industry. G. Mooney and A. Law. Bristol. The Policy Press: 189-208.

Leicht, K., Walter, T.; Sainsaulieu, I. and Davies, S. (2009). 'New Public Management and New Professionalism across Nations and Contexts.' Current Sociology 57(4): 581-606.

Mawby, R. and Worrall, A. (2013). Doing Probation Work. Abingdon, London: Routledge.

McKnight, J. (2009). 'Speaking up for Probation.’ The Howard Journal 48(4): 327-343.

MoJ (2015) National Offender Management Service Workforce Statistics Bulletin. Ministry of Justice.

Noordegraaf, M. (2016). Reconfiguring Professional Work: Changing Forms of Professionalism in Public Services.' Administration and Society 48(7): 783-810.

Pollitt, C. (2013). '40 Years of public management reform in UK central government promises, promises ...' Policy and Politics 41(4): 465-480.

Robinson, G., Burke, L. and Millings, M. (2015). 'Criminal Justice identities in transition: the case of devolved probation services in England and Wales.' British Journal of Criminology 56(1): 161-178. 
Robinson, G., Burke, L. and Millings, M. (2017). 'Probation, privatisation and legitimacy.' The Howard Journal 56(2): 137-157.

Smith, A. (2012). "'Monday will never be the same again": the transformation of employment and work in a public-private partnership.' Work, Employment and Society 26(1): 95-110.

Tangen, J. and Ravinderjit Kaur, B. (2018). 'The revolving door of reform: Professionalism and the future of probation services in England and Wales', Probation Journal 65(2): 135151.

Thomas, R. and Davies, A. (2005). 'Theorizing the Micro-politics of Resistance: New Public Management and Managerial Identities in the UK Public Services.' Organization Studies 26(5): 683-706.

TUC (2015). Outsourcing Public Services. London, Trades Union Congress.

Turner, S., Lourenço, A. and Allen, P. (2016). 'Hybrids and Professionals Communities: Comparing UK Reforms in Healthcare, Broadcasting and Postal Services.' Public Administration 94(3): 700-716.

Walkers, S., Annison, J. and Beckett, S. (2019). 'Transforming Rehabilitation: The impact of austerity and privatisation on day-to-day cultures and working practices in probation.' Probation Journal 1-16 doi.org/10.1177/0264550518820670. 
Table 1: Impact of Transforming Rehabilitation on professionals and professionalism

\begin{tabular}{|c|c|c|c|c|c|c|c|}
\hline $\begin{array}{l}\text { Survey question: What professional concerns } \\
\text { do you have following Transforming } \\
\text { Rehabilitation? } \\
\text { Instructions to respondents: 'Tick as many } \\
\text { as the following statements as you wish' }\end{array}$ & $\begin{array}{c}\text { National } \\
\text { Probation } \\
\text { Service } \\
\text { N/\% }\end{array}$ & $\begin{array}{c}\text { Community } \\
\text { Rehabilitation } \\
\text { Companies } \\
\text { N/\% }\end{array}$ & $\begin{array}{l}\text { Total } \\
N / \%\end{array}$ & $\begin{array}{l}\text { Probation } \\
\text { Officer } \\
N / \%\end{array}$ & $\begin{array}{l}\text { Probation } \\
\text { Service } \\
\text { Officer } \\
\text { N/\% }\end{array}$ & $\begin{array}{c}\text { Senior } \\
\text { Probation } \\
\text { Officer } \\
N / \%\end{array}$ & $\begin{array}{l}\text { Total } \\
N / \%\end{array}$ \\
\hline $\begin{array}{l}\text { Poor communication between National } \\
\text { Probation Service and Community } \\
\text { Rehabilitation Company }\end{array}$ & $\begin{array}{c}203 \\
48\end{array}$ & $\begin{array}{c}202 \\
68\end{array}$ & $\begin{array}{c}405 \\
56\end{array}$ & $\begin{array}{c}261 \\
56\end{array}$ & $\begin{array}{c}139 \\
55\end{array}$ & $\begin{array}{l}63 \\
48\end{array}$ & $\begin{array}{c}463 \\
54\end{array}$ \\
\hline $\begin{array}{l}\text { I have little opportunity to discuss my } \\
\text { work/cases with colleagues }\end{array}$ & $\begin{array}{l}141 \\
34\end{array}$ & $\begin{array}{l}95 \\
32\end{array}$ & $\begin{array}{l}236 \\
33\end{array}$ & $\begin{array}{l}181 \\
39\end{array}$ & $\begin{array}{l}60 \\
24\end{array}$ & $\begin{array}{l}32 \\
24\end{array}$ & $\begin{array}{l}273 \\
32\end{array}$ \\
\hline $\begin{array}{l}\text { I am unable to spend enough time with } \\
\text { individual clients }\end{array}$ & $\begin{array}{c}151 \\
36\end{array}$ & $\begin{array}{c}104 \\
35\end{array}$ & $\begin{array}{c}255 \\
36\end{array}$ & $\begin{array}{c}206 \\
44\end{array}$ & $\begin{array}{l}82 \\
32\end{array}$ & $\begin{array}{l}8 \\
6\end{array}$ & $\begin{array}{c}296 \\
35\end{array}$ \\
\hline I have little time for professional reflection & $\begin{array}{c}257 \\
61\end{array}$ & $\begin{array}{c}166 \\
56\end{array}$ & $\begin{array}{c}423 \\
59\end{array}$ & $\begin{array}{c}315 \\
67\end{array}$ & $\begin{array}{c}103 \\
41\end{array}$ & $\begin{array}{l}70 \\
53\end{array}$ & $\begin{array}{c}488 \\
57\end{array}$ \\
\hline I have a bigger caseload & $\begin{array}{c}140 \\
33\end{array}$ & $\begin{array}{c}108 \\
36\end{array}$ & $\begin{array}{c}248 \\
35\end{array}$ & $\begin{array}{c}195 \\
42\end{array}$ & $\begin{array}{l}68 \\
27\end{array}$ & $\begin{array}{l}26 \\
20\end{array}$ & $\begin{array}{c}289 \\
34\end{array}$ \\
\hline Targets are unrealistic & $\begin{array}{c}204 \\
49\end{array}$ & $\begin{array}{c}181 \\
61\end{array}$ & $\begin{array}{r}385 \\
54\end{array}$ & $\begin{array}{c}72 \\
281 \\
60\end{array}$ & $\begin{array}{c}121 \\
48\end{array}$ & $\begin{array}{l}47 \\
36\end{array}$ & $\begin{array}{c}449 \\
53\end{array}$ \\
\hline $\begin{array}{l}\text { I regularly have to cut corners/ compromise } \\
\text { professional standards to meet targets }\end{array}$ & $\begin{array}{c}153 \\
37\end{array}$ & $\begin{array}{c}107 \\
36\end{array}$ & $\begin{array}{c}260 \\
36\end{array}$ & $\begin{array}{c}208 \\
44\end{array}$ & $\begin{array}{l}66 \\
26\end{array}$ & $\begin{array}{l}30 \\
23\end{array}$ & $\begin{array}{c}304 \\
36\end{array}$ \\
\hline $\begin{array}{l}\text { Profit motive will corrupt traditional probation } \\
\text { values }\end{array}$ & $\begin{array}{c}323 \\
71\end{array}$ & $\begin{array}{c}237 \\
70\end{array}$ & $\begin{array}{c}560 \\
71\end{array}$ & $\begin{array}{c}341 \\
72\end{array}$ & $\begin{array}{c}165 \\
65\end{array}$ & $\begin{array}{l}84 \\
63\end{array}$ & $\begin{array}{c}590 \\
67\end{array}$ \\
\hline
\end{tabular}

Note: ' $\mathrm{N}$ ' = number of respondents stating 'yes'; \% = percentage of respondents stating 'yes' 